\title{
Definition of Technological Solutions Based on the Internet of Things and Smart Cities Paradigms for Active and Healthy Ageing through Cocreation
}

\author{
Alejandro Martín Medrano-Gil (D), Silvia de los Ríos Pérez, Giuseppe Fico (DD, \\ Juan Bautista Montalvá Colomer, Gloria Cea Sáncez, \\ Maria Fernanda Cabrera-Umpierrez, and María Teresa Arredondo Waldmeyer
}

Life Supporting Technologies, Universidad Politécnica de Madrid, Madrid, Spain

Correspondence should be addressed to Alejandro Martín Medrano-Gil; amedrano@lst.tfo.upm.es

Received 1 August 2017; Revised 5 December 2017; Accepted 2 January 2018; Published 30 January 2018

Academic Editor: Aitor Almeida

Copyright (C) 2018 Alejandro Martín Medrano-Gil et al. This is an open access article distributed under the Creative Commons Attribution License, which permits unrestricted use, distribution, and reproduction in any medium, provided the original work is properly cited.

\begin{abstract}
Existing initiatives to improve physical, mental, and social condition of senior citizens, which in Europe fall under the name of Active and Healthy Ageing, are including technological paradigms as main driver for innovation uptake. Among these paradigms, Smart Cities and the Internet of Things are of utmost importance. However, these initiatives may benefit from unified visions, efforts, and frameworks when it comes to defining technological solutions that take the most of both paradigms. We have defined an iterative approach, which combines user centred design techniques, technological development approaches, and a multifaceted adaptation process, to define a solution for Active and Healthy Ageing that makes use of the two paradigms. The solution is being defined in the context of two research and innovation projects, City4Age and ACTIVAGE, during which a solution is going to be defined and evaluated in the city of Madrid. Results show how Smart Cities and Internet of Things contribute to the solution, from a user (user needs and use cases) and a service delivery (technologies, architecture, and suppliers) perspective. In conclusion, we find the cocreation framework extremely useful for the Active and Health Ageing domain, and the proposed implementation of it is functioning, although there is room for improvement.
\end{abstract}

\section{Introduction}

Thanks to the advances and achievements in medical science and technologies, life expectancy and quality of life have been increasing worldwide during the last decades, and it is expected to increment further in the near future [1]. However, the latest global economic crisis and the increased proportion of the ageing population are showing that current health and social care systems are not adequate to guarantee physical, mental, and social well-being of their citizens, from childhood to late adulthood, the latter being the most challenging and most demanded. In this sense, cities can play a key role by favouring the opportunities for developments for a healthy, participative, and safe life [2]. In this context, the World Health Organization has defined Active and Healthy Ageing (AHA) as a process that includeschallenges but also oppor- tunities for health maintenance and social involvement of senior citizens, to preserve their quality of life as they age [35]. In Europe, the European Commission (EC) launched the European Innovation Partnership (EIP) on AHA initiative in 2011 [6], to accelerate the uptake of innovative solutions from health and social care systems. This initiative aims to implement research and innovation involving all relevant actors at different levels, European, national, and regional, with the aim of extending the good health of Europeans in two years of life by 2020 [7]. Within the EIP-AHA initiative, a conceptual definition of Active and Healthy Ageing has been proposed, which includes different characteristics such as physical and cognitive functionality, well-being, and social participation of the citizenship. This conceptual framework has been proposed to allow comparisons of interventions and other initiatives [3] carried out within the different European 
regions. However, this framework lacks specific definitions and methodologies to assess and compare technological solutions.

1.1. Solutions for Active and Healthy Ageing. Until few years ago, gerontechnology, an interdisciplinary field of research in which technology is applied to older persons, has been mostly focused on solutions for acute care, chronic diseases, and disabilities [8]. However, in the emerging European understanding of AHA, technological solutions have been associated with services that providers (in a regional or local context) have been defining in a more strategic context of prevention (trying to avoid illness and decline), compensation (when it is not possible to prevent or cure and only reduce the impact of the declined capacity), and care (when the deterioration cannot be prevented or compensated and requires care assistance) [5].

Technologies that are used for AHA, such as pervasive computing [9], ambient assisted living [10, 11], robotics [12], or serious games [13], have been implemented mainly to provide services in the homes of senior citizens, but rarely they have been implemented in other environments, like transport systems, public spaces, and other environments in the city or rural environment of the user. It is precisely in these places where AHA services are most needed, as more than half of the world's population lives in cities, and this trend is increasing more in the emerging countries and will continue during the following decades [14]. This fact, together with the ageing of the population, means that most of the inhabitants of the cities are getting older and require services that are adequate to their characteristics. Communities, or agefriendly cities, are defined as places where older people are actively involved, valued, and supported by infrastructures and services that respond effectively to their needs [15].

1.2. Smart Cities and IoT Solutions Related to AHA. The concept of Smart City (SC) begun to emerge a few years ago, and there are many definitions, although they are more focused on technology and infrastructures, than on citizens [14]. In Europe, the European Innovation Partnership for Smart Cities and Communities initiative started in July 2012. It aims to combine Information and Communication Technologies (ICT), energy management, and transport management to face the major environmental, societal, and health challenges [16]. These concepts have only been partially implemented into the reality of cities and do not specifically target senior citizens. To develop Smart Cities, "a larger understanding of urban infrastructure systems is necessary to move from data to information to knowledge and, ultimately, to action for urban sustainability and human well-being" [17]. And therefore, to seek the well-being of the citizen, Smart Cities must also take into account the needs of the older adults with the technology and with the intelligent city services, making the Smart Cities, smart age-friendly cities [18].

Smart Cities face many technological challenges, where by their systems need to interconnect services, sensors, and other components within the city. These challenges are addressed at a larger scale by the emerging paradigm of
Internet of Things (IoT). This paradigm proposes an open connected network of devices, sensors, processor units, data storage units, and other elements to build services for the users on top of them.

IoT provides innovative solutions to promote more efficient approaches in the AHA domain and has gained a great momentum as a key enabling technology for a wide range of applications and help older adults live independent lives [19]. The European Commission aims at demonstrating that IoT is a key enabler for the successful deployment of Smart Living solutions that positively affect Active and Healthy Ageing (AHA) [20]. Some of the IoT main characteristics such as Ubiquitous Connectivity, Pervasive Computing, and Ambient Intelligence are all highly related to AHA environments. Monitoring health status, delivering wellness interventions, and providing alert and information services are examples of how IoT is involved in the promotion of AHA [21].

In the context of the Alliance for Internet of Things Innovation (AIOTI) [22], an industry-driven association, promoted by the EC, to accelerate the implantation of IoT technologies in Europe, the Working Group (WG) 5-Smart Living Environment for Ageing Well [23] has analysed the challenges to be faced by IoT solutions in the AHA domain. These challenges have been defined around individual and environmental factors in both indoor and outdoor environments. Individual factors are those that contribute to prevent cognitive and physical decline [24]. Environmental factors are those related to daily living activities, such as housing [25], transport [26], mobility [27], or leisure [28]. The AIOTI WG5 has envisioned the realization of smart IoT ecosystems that minimize the danger of reduced care options or the requirement of a transitioning period that may affect negatively their active living and health.

Even though it has been recognised how the Smart Cities and IoT paradigms could positively contribute to address the most important challenges related to AHA [29], existing efforts and initiatives are still being deployed in isolated ways [30, 31]. The work described in this paper aims at contributing to this challenge by providing a consolidated and multifaceted iterative cocreation framework to create technological-based solutions for AHA that build on top of the Smart Cities and IoT paradigms.

The definition of such solution has been carried out in the context of two research and innovation projects, in which technological solutions are going to be tested, deployed, and eventually adopted in the city of Madrid, where, recently, an investment of $903,000,000 €$ dedicated to meet the needs of the older adults has been announced, to transform Madrid into an age-friendly city [32].

\section{Materials and Methods}

2.1. The City4Age and ACTIVAGE Projects. City4Age $[33,34]$ is a European research and innovation project, funded by the European Commission, which aims to enable ambient assisted (or age-friendly) cities, through a range of ICT tools and services that supports Active and Healthy Ageing and allows early detectionof risks related to cognitive 
deterioration or frailty of senior citizens. Smart Cities are able to detect a wide range of data about individuals' behaviours, coming from different sensors as well as open data, letting us to identify population at risk, monitor daily life activities of identified users in a smart environment, and provide personalized interventions. These interventions are critical in order to foster positive behaviours (such as walking, doing some physical exercise, or going to meet a friend) or take action in case of negative change of behaviour, especially those that may lead to a deterioration of cognitive and/or physical conditions, helping in the early detection of related diseases.

The project is being implemented in six testbeds locations: Athens (Greece), Birmingham (United Kingdom), Madrid (Spain), Montpellier (France), Lecce (Italy), and Singapore (Singapore), where solutions are deployed in different use case scenarios covering indoors (at home or within a senior centre) and outdoors (along the city).

Concretely, this paper is focused in the Madrid pilot site as case study for the first phase of the methodology described, having as output a solution in a Smart City context. In the Spanish testbed, the focus is to identify behaviours through the mobility of the user within the city of Madrid, by acquiring data coming from different sources including multiple hardware and sensors (i.e., smartphone, smart wristband, Bluetooth beacons, etc.) and Smart City information (i.e., from public bus transportation, weather conditions).

The solution is currently being tested with 20 participants (7 male, 13 female), who are independent, aged over 80 years, regular and autonomous users of public transportation buses within Madrid city centre area, and relatively familiar with technology (usage of smartphone). And even though the frailty is not actively measured, they could be considered between 1 and 3 in the Fried Frailty Index. Participants are given a smartphone (models used in the study are Samsung Galaxy S4, S5, and S5 mini, and Samsung J5), a smart wristband (i.e., Fitbit Charge 2), and 2 Bluetooth Low Energy (BLE) beacons (i.e., Estimote). Testing started with 5 participants and incrementally increased its number until the total number of 20 elderly. Trials are performed as a continuous testing which started in February 2017 and will last until June 2018.

ACTIVAGE is a Large Scale Pilot Project, funded by the European Commission with the objective of building the first open IoT ecosystem for AHA. Solutions are being tested around 9 reference use cases: activities of daily living, integrated care, monitoring outdoor, emergency triggers, promoting exercise for fall prevention, preventing cognitive decline, preventing social isolation, offering safety and comfort, and support for transportation.

The different solutions will be implemented across 9 deployment sites distributed in Spain, France, Italy, Germany, Greece, Finland, and United Kingdom. Each site will carry out a subset of use cases, evaluating the actual value they provide to the market and end users.

Interoperability is a key aspect, not only for the systems, but for the ecosystem too, as it allows for easer deployment and operation of IoT-based AHA solutions. Thus one of the main outcomes will be a secure IoT interoperable layer (for integrating applications and platforms at different levels), as well as service layer (offering support for a marketplace and application support tools).

In this case, the deployment site in Madrid is the focus of this paper, which is used as case study for the second phase of the cocreation framework presented in the paper, having as output a Smart Cities and IoT solution for AHA. The solution is currently under implementation and will be tested with about 1000 participants, who are above 65 years old, with scale frailty between 1 and 6 (in the Fried Frailty Index), and with no cognitive problems and who can receive assistance from formal caregivers at home or at a day care centre. Participants will be given a smartphone (i.e., Samsung Galaxy S5) and some IoT devices depending on the concrete use case to test (devices may include smart wristband-FitBit, NFC tags, IoT lamp, eBeacons, and/or door sensor). Testing will be performed in incremental iterative phases. Each new phase will include new services and new IoT elements as well as more stakeholders who will be involved to the Madrid deployment site while it evolves, with the objective to achieve an AHA-IoT sustainable ecosystem.

The complete case study presented in this paper consists of the whole process followed through the cocreation framework proposed, divided into two phases:

(i) a technological solution for Smart Cities (in the context of the City4Age project-first case study), which is used as input for the second phase;

(ii) a technological solution for Smart Cities and IoT (in the context of the ACTIVAGE project-second case study), which is the final outcome of the methodology proposed.

2.2. The Cocreation Framework. A cocreation framework has been used to gather user requirements in collaboration with end users and stakeholders. The Logical Framework Approach [35] has been used as main reference. This method, widely used in cooperation and cocreation projects, gives considerable importance to the analysis and diagnosis of the community and their experience [36]. It has been used with the objectives of identifying the basic information required from users and stakeholders in order to gather their needs and preferences [37,38] and address them when designing or implementing an intervention. In our work, the Logical Framework was adopted to extract information from a user perspective [20] and with the aim of determining the following elements (as depicted in Figure 1):

(i) User needs: related to a product or service and the fact that the product or service must be satisfied to get the right outcome for them and meet goals and aspirations of the user.

(ii) Use cases: a set of possible sequences of interactions (scenarios) between systems and users in a particular environment and related to a particular goal.

(iii) Solution: a combination of a service (provided by the demand side) with a technology (provided by the supplier side). 


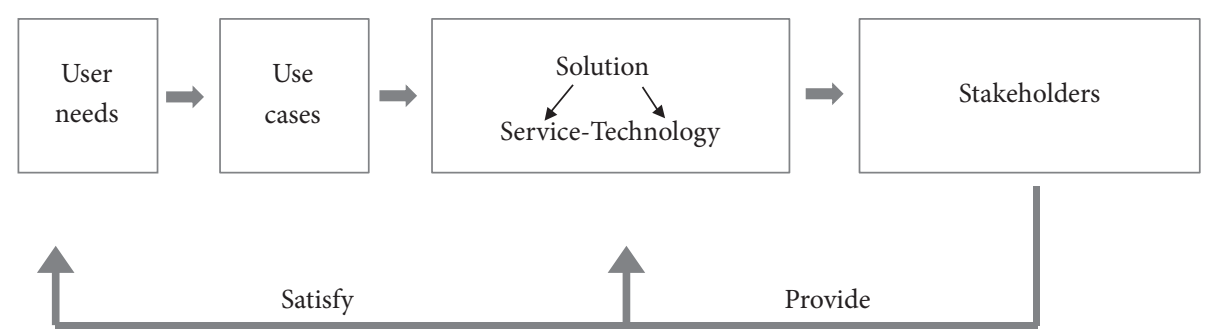

FIGURE 1: The cocreation framework, the building block of the iterative approach to derive the solution.

(iv) Stakeholders: actors or group of actors that are providing a contribution to the solution in the related ecosystem.

The second building block of the methodology, used to further process the elements from a technological development perspective, consisted of three phases, analysis, adaptation, and assessment. During each phase, the elements of the cocreation framework were reviewed and redefined, and specific values were eventually extracted. This process is designed according to the experience that was gathered from previous initiatives and projects $[39,40]$, then expanded with related literature, and finally consolidated through interviews and focus groups with end users and stakeholders.

The three phases are based on a simplified waterfall model [41], with some integrated feedback. Thus the execution is not a rigid lineal execution; in fact it allows at different points going back to previous steps (e.g., if, for some reasons, one step is executed before the planned one, a meeting with a stakeholder can take place before and after presenting the solution). This might be useful when the process detects potential problems before the overall solution is deployed.

During the analysis phase, we compare services and solutions available in the market with what is required to satisfy the users' actual needs. The objective is to produce a comprehensive plan of execution to deploy a new and/or improved solution.

During the adaptation phase, the required technologies and services as defined by the analysis phase are selected, reconfigured, and deployed. The objective is to develop an implementation that can be evaluated in the next phase and used as final choice for the first iteration.

During the assessment phase, the solution is inspected in order to see whether it fits the user needs. The evaluation is carried out along different axes such as technological, economic, human, social factors. The objective is to validate the solution and ensure it will satisfy the user needs in an efficient and economically viable way. In the first iteration, heuristic evaluations, usability tests, interviews, and focus groups are enough.

Each of the three phases is composed of different tasks and activities at the level of the element of the cocreation framework, as shown in Figure 2.

Requirement extraction analyzes the requirements for the adapted solution, and the focus of these requirements derived mainly from the validation with users; interviews, focus groups, and questionnaires supported by demos or mock-ups of the end solution have been used to define and map user needs and expectations with values, attributes, and requirements. As regards the values, their function is to answer the question on how the final solution, and the paradigm it is based on, actually improves the lives of the end users. This task will produce a set of key concepts that will be then used as main dimensions and research questions to be used during the evaluation and validation activities.

Use case definition formalizes the conclusions of the analysis phase in a set of use cases (UCs) [42, 43]. There are different levels of formalization, and there can be some abstract and generic use cases, which rather describe the concrete solution and the benefits of using the paradigm, highlighting the added values. Specific UCs also need to be defined for the service definition and system development tasks. While defining the UCs, the process might require a revision of the requirements, as specification of UCs probably poses new questions that were not considered. Any new UC added to the final set will always trigger an analysis of existing resources, to scout for technologies and concepts which may help in the implementation or refinement of the said UCs. UCs might also be handled as part of available resources, and these can be reused directly or adapted to the requirements.

Analysis of available resources is a crucial task, as it will inevitably help reduce the costs of adapting and developing a solution. The objective is to research the market for all the resources needed for the solution, and these might include complete solutions, running services, existing use cases, business models, technologies (such as libraries, frameworks, and platforms), and even competitor solutions.

Negotiation is necessary to avoid problems. The cocreation framework requires stakeholders to participate in the process. This will on one hand improve the solution, as only certain stakeholders have the knowhow for specific UCs. On the other hand, it will help to avoid designing solutions relying on commitments that later may not be fulfilled (for example, a full solution could be designed assuming a particular service was going to be provided, but when contacting the stakeholder responsible for the said service, it is discovered that the service is unavailable or provided in a different manner as expected).

Service definition is required to derive from the UCs into the different aspects both the technology and the service provision which needs to be fulfilled. The main objective is to coordinate the integration between technologies and the service, as well as (re)defining the provided services. Some times during this process relevant requirements that are not 


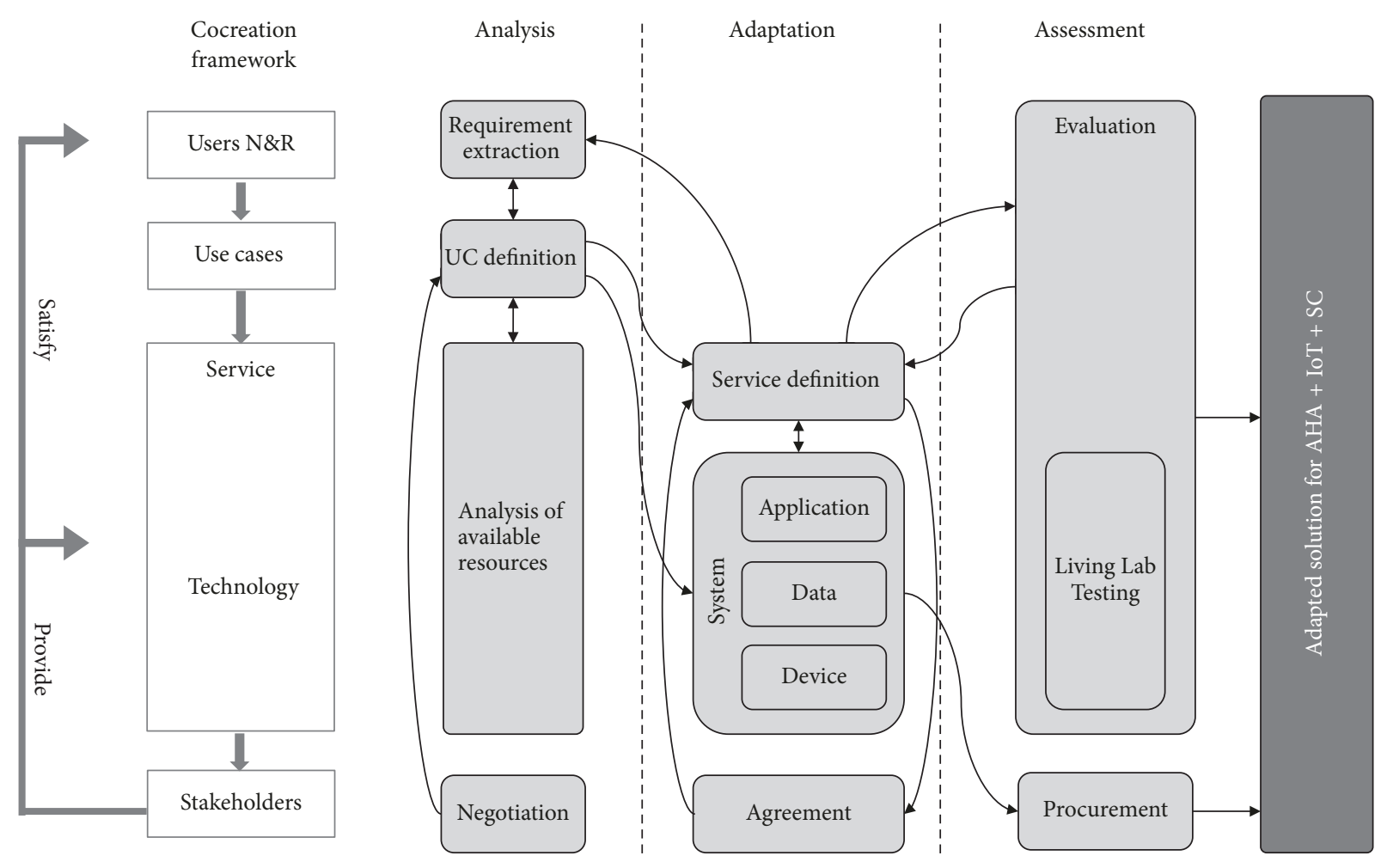

FIgURE 2: Overview of activities and tasks executed during the cocreation framework and their dependencies.

defined are discovered; in this case it is advisable to review the requirements using the methodologies employed in the previous phase.

System development encompasses all the technology development process. Any system development methodologies may be used, preferably those based on UCs and requirements as those have been defined in the previous phase. Special attention should be paid to the most critical aspects of the system:

(i) Application, the software itself, and the logic of the technology system will implement the UCs.

(ii) Data and data flows need to be defined and analysed. Security and privacy must drive this subtask, ensuring that the users' rights are enforced, and one good example of legislation to take into account is the European General Data Protection Regulation [44].

(iii) Device level development may be considered separate to the other two subtasks of the system development, yet it needs to integrate with both the application and general data flows of the system.

Agreement from the different stakeholders has to be reached. The terms of the services provided, the needed adjustments, and economic aspects need to be ratified. In contrast with the negotiation task, where the role of each stakeholder is to help in the design of the solution, this task is meant to plan the structures and processes needed from the different stakeholders to enable the end solution to work seamlessly.

Evaluation is required in order to verify that the solution is working as intended, solving the actual problems in an efficient and economically viable way. First the methodology is set, by defining an evaluation framework, then the task needs to run the evaluations in order to obtain the indicators. When designing and running evaluations, a small scale test must be included; we conduct ours in the Living Lab [40], where we can run the technologies and services in a controlled manner, as well as being the perfect environment for inspecting the behaviour and the interaction of the users towards the solution. During evaluation, and if it is correctly synchronized in time with the other tasks, the probability of finding issues and bugs in the system, services, and integration between both is very high; thus this task must report to the other tasks in order to improve the solution.

Procurement is the process by which the stakeholders prepare their structures to provide the service. This may include the negotiations with suppliers for acquiring the different required materials and devices, as well as hiring staff, training, and setting up the legal processes (consent forms, service contracts, etc.).

2.3. Study Description. The process was used first to define a solution in a Smart City context, within the City4Age project. We took existing commercially available solutions (i.e., smartphones, smart activity wristbands, and Bluetooth beacons) and services (i.e., Google and Google Maps API, Spanish National Weather Open Data, from AEMET, Madrid Transport Open Data and WiFi from Madrid public transport buses), together with the Smart Cities paradigm to create a solution addressing specific AHA related problems. This output was used as input in the framework of the ACTIVAGE 


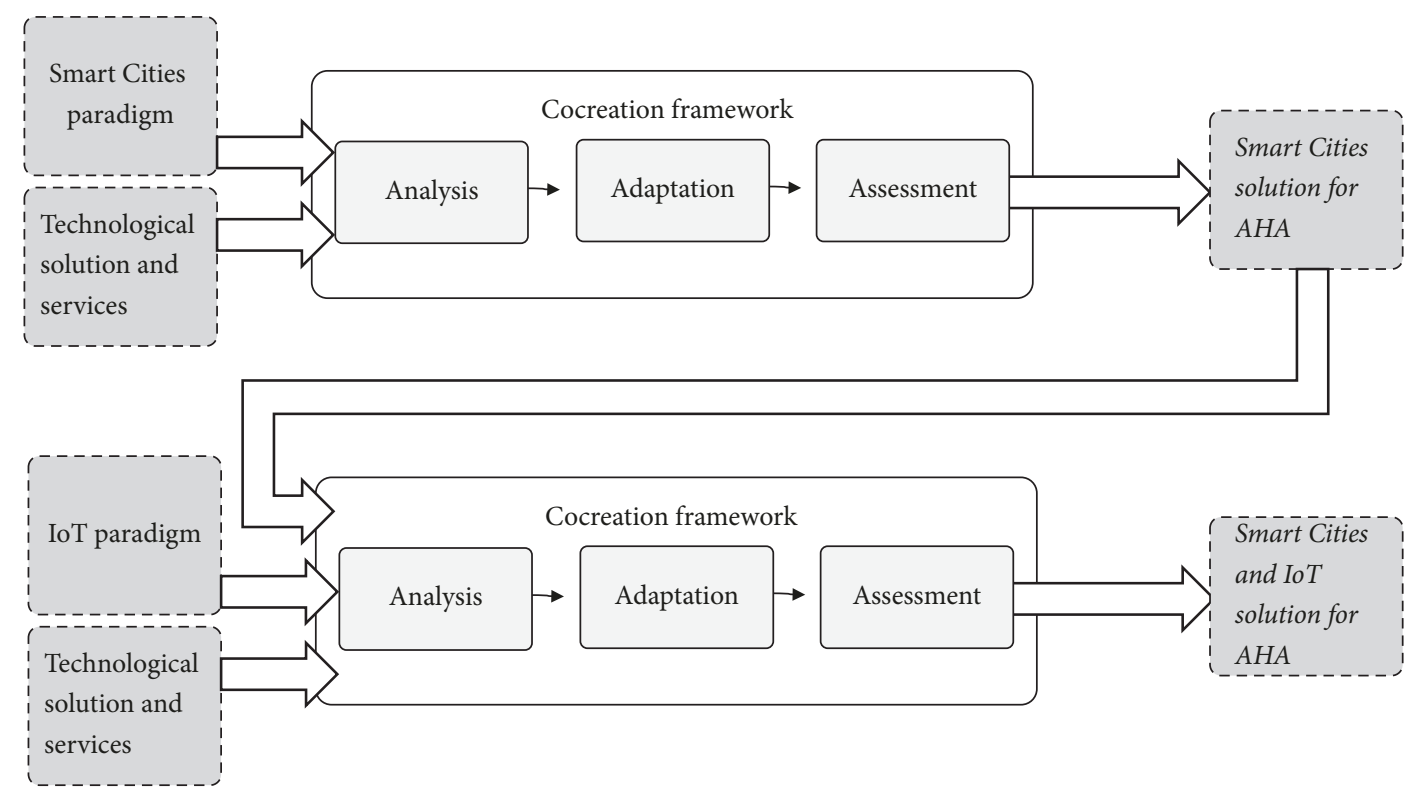

FIGURE 3: Simplified overview of the application of the methodology adopted and how it was applied for our study. As of the writing of this manuscript, the Smart Cities solution is in the assessment phase, where the Smart Cities and IoT solution is in adaptation phase.

project, where we took most of the solution and applied the process again using the IoT paradigm together with other technologies and services. An overview of this process can be seen in Figure 3.

In the first iteration, user needs were extracted from analyzing documentation of the project developed by experts from the medical area (i.e., geriatricians and caregivers) within the project consortium. These documents provided Frailty and Mild Cognitive Impairments (MCI) risk models, based on validated instruments to assess frailty and/or MCI in older adults such as Fried Frailty Index [45] and the Lawton Instrumental Activities of Daily Living (IADL) Scale [46] and define a list of geriatric factors and subfactors to identify $\mathrm{MCI} /$ Frailty related behavioural models.

In addition, two informal interviews were carried out with two different types of stakeholders related to the Madrid municipality (see Table 1 and Table 2 for details):

(i) Two representatives from the public transport organizations (i.e., one from the Municipal Transportation Company of buses (EMT) and another one from the Regional Consortium of Public Transportation of Madrid (CRTM)).

(ii) A manager from a private elderly care service provider in relation to many day care centres in Madrid.

UCs were defined after negotiation with all involved stakeholders. They served to design the solution that was developed, by adapting existing solutions to the Smart Cities paradigm, as well as applying the lessons learned with the results of the analysis phase. Geriatric factors and subfactors identified in the analysis phase were matched against poten-
TABLE 1: Summary, during the analysis phase, of stakeholders and organizations involved in the study.

\begin{tabular}{lcc}
\hline Stakeholder type & Organization & Role \\
\hline $\begin{array}{l}\text { Municipal } \\
\text { Transportation } \\
\text { Company of buses }\end{array}$ & EMT & Responsible of mobility \\
\hline $\begin{array}{l}\text { Regional Consortium of } \\
\text { Public Transportation of } \\
\text { Madrid }\end{array}$ & CRTM & $\begin{array}{c}\text { Principal Technician of } \\
\text { the Accessibility Area }\end{array}$ \\
\hline Social service provider & $\begin{array}{c}\text { Tercera Edad } \\
\text { Activa (TEA) }\end{array}$ & $\begin{array}{c}\text { Madrid social researcher } \\
\text { and private care service } \\
\text { provider }\end{array}$ \\
\hline Technology provider & $\begin{array}{c}\text { UPM } \\
\text { research } \\
\text { group }\end{array}$ & $\begin{array}{c}\text { Technology research and } \\
\text { provider }\end{array}$ \\
\hline Government & $\begin{array}{c}\text { Madrid } \\
\text { social } \\
\text { services }\end{array}$ & $\begin{array}{c}\text { Public care service } \\
\text { provider }\end{array}$ \\
\hline
\end{tabular}

tial available data coming from existing technologies, devices, and infrastructures in the city of Madrid. This matching allows us to identify behaviours that are relevant for frailty and MCI detection. In order to develop an effective solution that enables the interaction between the relevant open data, technologies, and devices, the architecture of the Madrid pilot was defined and implemented as described in [46, 47]. During this process of development and adaptation, several meetings with stakeholders were organized (i.e., with representatives of the Madrid public company for buses (EMT) and general public transportation consortium (CRTM)) with the aim of defining the services and solve technical problems about integration of public buses WiFi and public transport open data services. In parallel, an agreement with the public 
TABLE 2: Summary of the demographics of the interviews and focus groups executed during the analysis phase.

\begin{tabular}{lcccc}
\hline Tool & $\#$ & Age & Gender & $\begin{array}{c}\text { Education level } \\
\text { (ISCED 2011) }\end{array}$ \\
\hline $\begin{array}{l}\text { Informal interview } \\
\text { transport }\end{array}$ & 2 & $41-48$ & $2 \mathrm{M}$ & $6-7$ \\
$\begin{array}{l}\text { Interview care } \\
\text { service }\end{array}$ & 1 & 56 & $1 \mathrm{~F}$ & 7 \\
FG end users & 5 & $66-72$ & $2 \mathrm{~F}$ & $5-7$ \\
FG formal carer & 4 & $36-49$ & $2 \mathrm{~F}$ & $5-7$ \\
$\begin{array}{l}\text { FG } \\
\text { multidisciplinary }\end{array}$ & 6 & $27-29$ & $3 \mathrm{~F}$ & $3 \mathrm{M}$ \\
$\begin{array}{l}\text { Interview } \\
\text { municipality }\end{array}$ & 1 & 47 & $1 \mathrm{~F}$ & $5-7$ \\
\begin{tabular}{l} 
Interview manager \\
\hline
\end{tabular} & 1 & 54 & $1 \mathrm{~F}$ & 3 \\
\hline
\end{tabular}

buses company in Madrid (EMT) and a private service provider for elderly care was established.

To proceed with the assessment phase, an evaluation framework process was designed, consisting of a technical validation and a real life experiment with elderly participants. The validation of the solution is used to assess the technology, its acceptance by the users, and its validity from a geriatric point of view. Technology will be assessed through laboratory and real life pretests, user acceptance will be assessed through focus groups and questionnaires, and geriatric assessment will be conducted through interviews.

The solution was technically tested in the Smart House Living Lab $[47,48]$, together with the Campus of International Excellence of Moncloa [48, 49], as a Smart City Living Lab, before taking the solution to real life environments in the Madrid test bed, within the City4Age project. This real life testing is currently being carried out. After an explanation about the project and the corresponding signature of the informed consent, participants of the trials are given the necessary equipment (i.e., one smartphone, one smart wristband, and two Bluetooth beacons) and are asked to carry out the mobile and wristband devices with them, while beacons are placed at the entrance of their house as well as in their mail box to detect whether the user is at home. They should keep the solution for at least 6 months.

For the second iteration, a series of focus groups, with end users, and associations of end users, as well as with stakeholders, were organized, in order to cover as many actors as possible. Focus groups were organized as follows (for demographics please refer to Table 2):

(i) 1 focus group with end users who are clearly involved in Active and Healthy Ageing activities, such as getting involved in their community activities, keeping a healthy diet, and doing regular exercise.

(ii) 1 focus group with formal caregivers, working in a service provider private company, all of them with more than 10 years of experience and all of them having worked both in homecare providing and in day care centres.

(iii) 1 focus group with a multidisciplinary technical team with several years of experience in the development of applications for health, AHA, and social wellness, who are currently active participants in European projects in the areas of ICT for health of people with chronic diseases and older adults.

In addition, two structured individual interviews were carried out with two different stakeholders (see summary of stakeholders in Table 1):

(i) A municipality responsible for social services, with 50.000 inhabitants, high level standard of life, $20 \mathrm{~km}$ from Madrid. 10\% of their population is older than 65 years.

(ii) A manager for day care centres, and home care of a very important social services provider private company in Madrid.

The results of all these actions were used to redefine the specific use cases and thus design the technological solutions in the most appropriate way. There were generic use cases defined at ACTIVAGE project level, which were useful to classify the different elements of the solution. Technologies were analyzed, especially those which fitted the IoT paradigm as defined in the ACTIVAGE project.

In the adaptation phase, the services were defined with stakeholders, and agreement to the commitments each would acquire was reached, stakeholders (like the municipality of Madrid, as well as senior care private partner). Definition of the software services was done in an iterative way, by using ACTIVAGE use cases as initial classification, later reefing this classification into solutions which encompassed the different applications. Some applications were horizontal to all UCs. Most of the new required services were easily implementable as a set of rules using a production rule system, reusing the data from existing applications. The rest of the system development mainly consisted of adding an interoperability layer to many components and adding minimal number of original components to make the interaction easier for the user.

At the time of the writing of this paper, the projects have not yet entered in the assessment phase; thus no results of this phase are reported. The plans for this phase include Living Lab testing with the whole system (using the same infrastructure as the first iteration), as well as replicating the solution, or parts of it, to be implemented and reused in other deployment sites within the ACTIVAGE project. The system will gather many parameters from the users; we will use these to evaluate the improvement on their quality of life, together with other direct measurements such as questionnaires. A study has been designed to ensure the data collected and the conclusions derived from such data are both statistically significant and scientifically valid. The evaluation framework included many axes of interest, such as economic, technical, and social factors; the focus of the ACTIVAGE project is to measure the improvement of the quality of life of individuals through IoT technology. 


\section{Results}

3.1. Smart Cities Solution for AHA. The main conclusion from the analysis of user needs is that cities can play a key role to improve early detection of risks related to cognitive impairments (MCI) and frailty, because important efforts are currently being done by municipalities to engage citizens through collaborative activities in different environments, such as platforms for participative funding to carry out projects in the municipality $[49,56]$ or neighbourhoods associations for cultural activities $[50,56]$, and cities offer infrastructures and services with a high potential to support Active and Healthy Ageing of their citizens, such as smart services in public transportation, like guiding and support for people with disabilities, and older adults.

Regarding available resources, in terms of technologies and tools, taking as basis the analysis of the six test beds of the City4Age project, we have found that available solutions in Smart Cities can be reused to be implemented in use cases of different nature within a city, in both indoor and outdoor scenarios, covering different aspects of daily activities, such as mobility; independent living; regular performance of routine activities (shopping, bank, pharmacy, etc.); safety; socialization (and prevention of isolation).

Solutions to be adapted and developed in the context of a Smart City, outcome of the adaptation phase, are meant to cover the identified user needs related to the abovementioned aspects of daily life activities, which facilitate data analysis for a better personalization and adaptation of the services offered, in particular for the detection and analysis of behaviours, and for the delivery of interventions which are dependent of these behaviours. More in detail, the following use cases were defined:

(1) Motility (e.g., geriatric factor defined as physical mobility of the user such as walking, climbing stairs, and still/moving).

(2) Basic Activities Of Daily Living (e.g., dressing, selffeeding, personal hygiene, and going out).

(3) Instrumental Activities of Daily Living (e.g., ability to cook food, housekeeping, phone usage, shopping, and transportation usage).

(4) Socialization (e.g., visits to family members, attending senior centres, or other points of interest (POIs)).

As regards the solution, it is composed of two main elements: the first is a detection application, a mobile application that uses the different sensors of the smartphone and connects with the sensors and open data services available in the environment. This application tracks the mobility of the users within the city, including visited POIs and some of the activities performed, such as visit a familiar, and also their usage of public transportation (i.e., buses). The second element is a Dashboard, a web application that shows behavioural information of elderly users in a visual way. It is meant to be used by geriatricians and/or caregivers and it provides the information related to the behaviour of each user with a level of granularity that allows seeing the different measures associated with each activity identified (e.g., walking and speed, distance, and number of steps). It allows them to create interventions to be delivered through

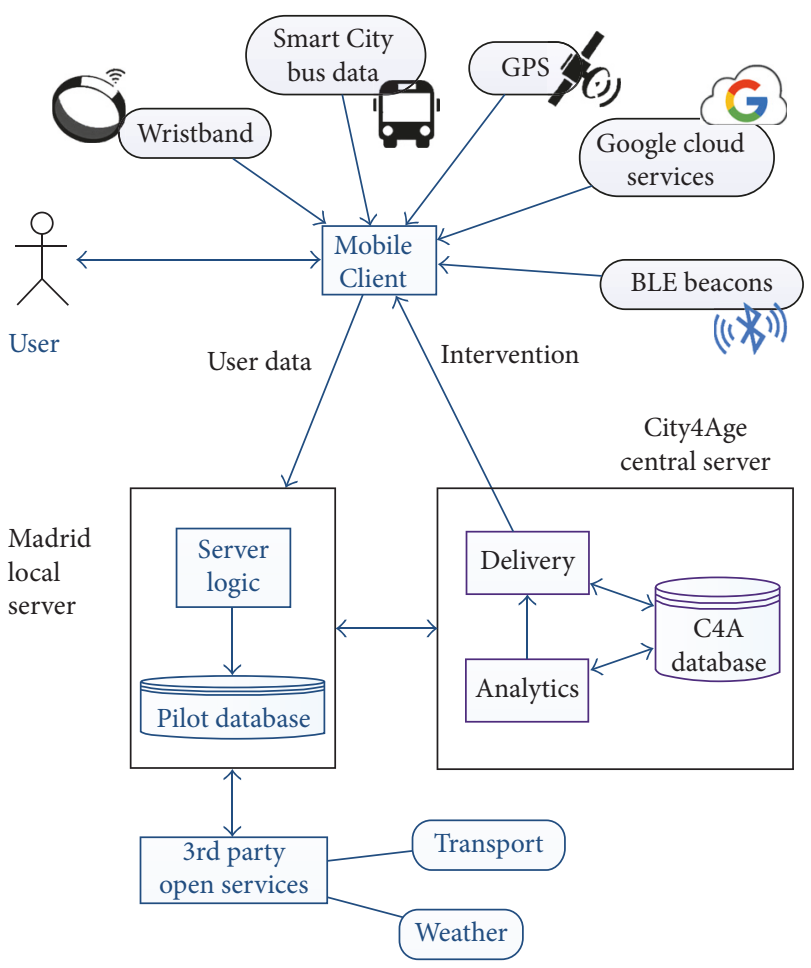

FIgURE 4: Overview of the Smart City system.

text messages or other media (e.g., SMS, e-mail, Facebook Messenger, Telegram, WhatsApp, and Push notification).

Figure 4 represents an overview of the architecture of the system for the Madrid test bed.

This solution is currently being tested with 20 elderly participants (under the conditions mentioned in Section 2). Trials started in February 2017 by collecting data from participants using the detection application. Evaluation will be performed in 2018 by measuring and analyzing the following variables and using the materials mentioned in Table 3.

Within the evaluation process of the City4Age, we measure the engagement of the users with the different services through the collected data in terms of measures and actions gathered by the different devices. As we are collecting user data, we can analyze how the users interact with the application through the metrics gathered about the usage of the devices. This also gives us information on the behaviour of the user and how the user follows the suggestions provided (i.e., interventions) through the system.

In addition, in order to evaluate whether the services deployed in the Madrid pilot are useful and fulfil the needs of elderly people and assess its acceptance, the different questionnaires about usability, usefulness, and ease of use mentioned in Table 3 will be tested with participants bimonthly from January 2018.

The detection application, the Dashboard as well as insights coming from the evaluation of the system in this first phase, will be used as input to the second phase within the context of the ACTIVAGE project. 
TABLE 3: Variables incorporated in the evaluation framework of the Smart City for AHA solution.

\begin{tabular}{|c|c|c|}
\hline Variables & Description & Material \\
\hline Speed & $\begin{array}{l}\text { Mobility patterns, average of } \\
\text { instantaneous speeds within walking } \\
\text { session }\end{array}$ & GPS, mobile phone \\
\hline Distance & $\begin{array}{l}\text { Mobility patterns, distance covered } \\
\text { during walking session }\end{array}$ & GPS, mobile phone \\
\hline Steps & $\begin{array}{l}\text { Mobility patterns, number of steps } \\
\text { between rest times }\end{array}$ & $\begin{array}{l}\text { Google API service based on mobile phone } \\
\text { inertial sensors }\end{array}$ \\
\hline Visits paid & $\begin{array}{l}\text { POIs interaction, number of visits paid to } \\
\text { a POI }\end{array}$ & GPS, mobile phone, Google Maps API \\
\hline Visits duration & $\begin{array}{l}\text { POIs interaction, duration of visits paid } \\
\text { to a POI }\end{array}$ & GPS, mobile phone, Google Maps API \\
\hline Grip strength & $\begin{array}{l}\text { Physical test, grip strength measured } \\
\text { every 2-3 months }\end{array}$ & Dynamometer \\
\hline Cognitive status & Cognitive test standardised & SHARE.FI [50]: instrument based on web tool \\
\hline Cognitive status & Cognitive test standardised & Mini-COG [51] as defined by S. Borson \\
\hline Cognitive status & $\begin{array}{c}\text { Cognitive test standardised, male and } \\
\text { female variation }\end{array}$ & $\begin{array}{l}\text { SPMSQ-VE [52]: Spanish version protocol } \\
\text { from Martinez et al. }\end{array}$ \\
\hline Interaction & Heuristic test, good interaction design & Nielsen heuristics [53] \\
\hline Usability & Usability test, technology acceptance & SUS questionnaire [54] \\
\hline Usefulness & Usability test, technology acceptance & TAM scale [55] \\
\hline Ease of use & Usability test, technology acceptance & TAM scale \\
\hline
\end{tabular}

3.2. Smart Cities and IoT Solution for AHA. After the first iteration for the solution application in Smart Cities, analysis of user needs with regard to IoT, as resulting from the focus groups, showed that users prefer services for AHA to be provided in those places in which they move habitually, like the library or the gym, instead of traditional day care centres. In order to cover a wide range of places, using IoT, where users perform their daily life activities, unobtrusiveness and transparency are key features to offer these services throughout a city, and they should only be activated when they are really necessary. Activity recommendations should be personalized to each user to assure best engagement. In addition, technological solutions must be reliable since a single failure could cause them to distrust and abandon the usage of the solution.

These results helped to redefine use cases for the pilot site in Madrid and identify key elements of the IoT stack to address consumer needs, through the addition of confident, transparent, and effortless components, while preserving, if not increasing, their value for privacy and security and trust. Another important element to be included is associated with reusability of technology and services across use cases. It is especially important to highlight that all elements of the cocreation framework are disengaged among them, which enables a high flexibility and adaptability of the system.

For the adaptation phase, the key activity was to define a series of services, according to the identified user needs, which extend the use cases developed during the iteration for Smart Cities adaptation:

Social Tracking. It analyzes the social interactions and activities performed by the user. This information is used for other services like evaluating isolation factors or behavioural analysis. The service promotes social activities by detecting those with higher engagement by the user. This service extends the scope of the Socialization UC.

Physical Activity Tracking. It analyzes the level of physical activity for each user, also compounding with its evolution over time and context. The service will promote users to engage in their preferred activities, in accordance with the user's level. This service extends the scope of services for motility UC.

Behavioural Analysis. It analyzes behavioural patterns in order to later be able to detect changes in these patterns which might indicate some cognitive degradation is taking place. Behavioural patterns are also used to determine the best way and time to perform interventions. This service mainly combines services to cover Basic Activities of Daily Living and Instrumental Activities of Daily Living.

Fall Risk Assessment. It analyzes the data from different sources, including the balance factors and level of physical activity as well as other factors which may influence the probability of falling like depression. Bearing in mind that during 


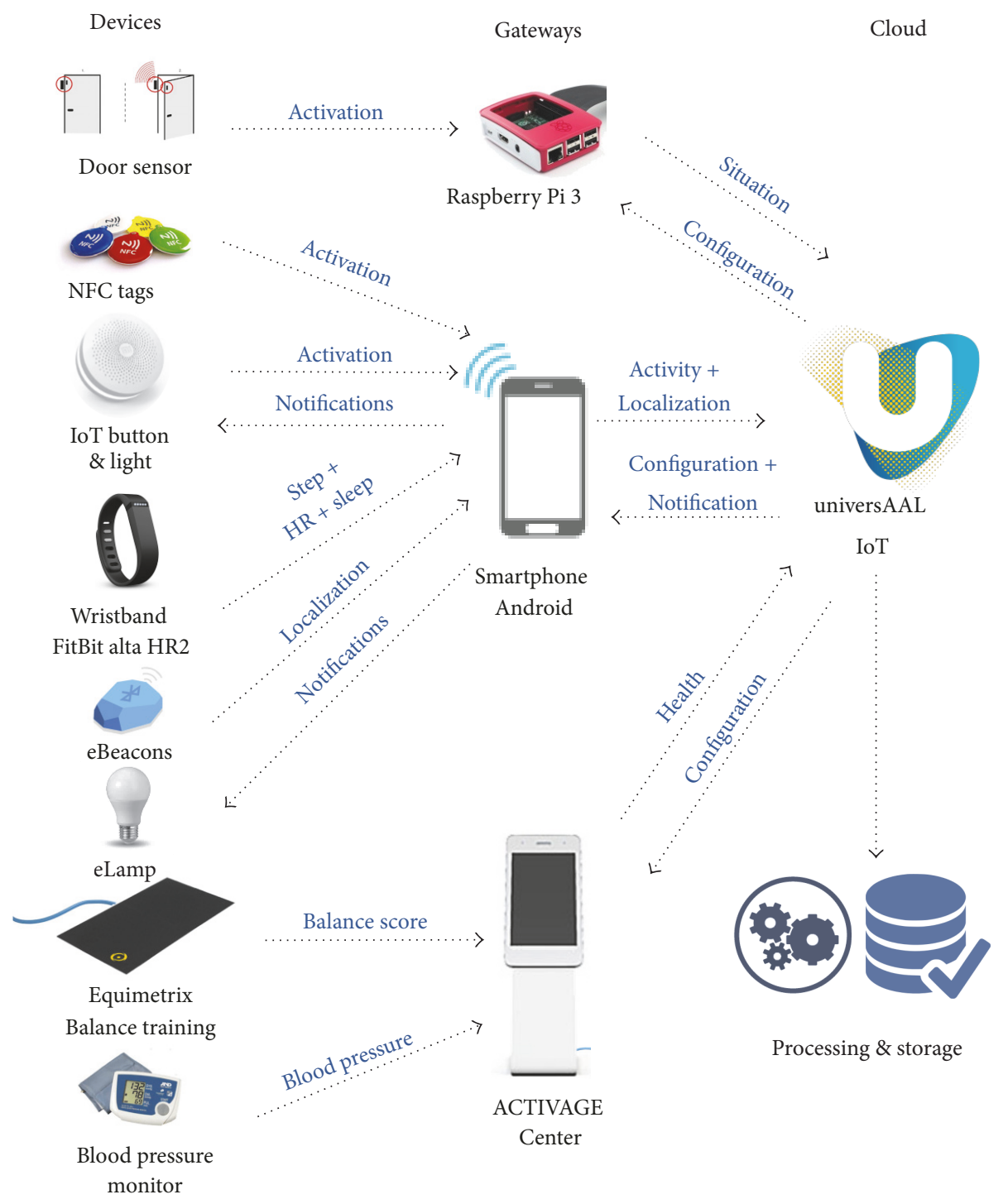

FIGURE 5: ACTIVAGE architecture of deployment site of Madrid.

the first iteration analysis of motility has been identified as an important geriatric factor to detect early signs of frailty or MCI, this UC has been extended with the aim of preventing falls in outdoor environments.

Isolation Risk Assessment. It analyzes the engagement of the user with their close social environment as well as their ability to increase their circle. Early detection of isolation risks will avoid certain problems. Specific actions performed by the service, other than promoting social events, are scheduling interviews with social workers or persuade the family to drop a visit. This service extends the scope of the Socialization UC.

Outdoor Tracker. It analyzes the behaviour of the user when outdoors, looking into walking patterns to detect erratic navigation which might indicate the user is lost. Missed stops and other sources of information might be useful to profile the user's abilities outdoors and activate procedures for swifter response, as assistance will be provided, when solicited, by sending a social worker or an informal carer to look for the user in distress. This service combines and extends the UCs previously defined about Motility and Basic and Instrumental Activities of Daily Living.

Intervention. Interaction with the user must be unified under one service, as this will help the user establish familiarity and trust in the system. There are many intervention channels (such as telephone calls, SMS, and LED light notification) and strategies. This service aims to extend the intervention solution (i.e., Dashboard), developed as outcome of the previous iteration, with new channels and interaction modalities.

For all these services to be provided and taking into account UCs, the system is being designed accordingly, as shown in Figure 5. 
Managed data can be categorized into 3 classes. Health data comprises the information about heart rate, blood pressure, and balance factor. Activity data is composed of usage information, sleep cycles, and number of steps. The last class of data managed is location data, which is gathered through the smartphone's integrated GPS, proximity to BLE beacons, or connectivity to a set of Wi-Fi signals; location data does not need to be very granular, or precise, as on one hand it helps maintain users' privacy, and on the other hand it is enough to know the point of interest the user has visited to offer the different services.

The key feature of the designed architecture is the distribution, partly because of the need to deal with the mobility of the user, as users can typically be on their home, moving throughout the city, or at specific places, also known as points of interest, like gymnasiums, libraries, and day care centres. Thus the system is designed to handle these three scenarios: there will be a set top box at the home of the user. The user will be carrying a smartphone, and there will be a set of information kiosks (which we call ACTIVAGE Centres) where users can perform different activities. These scenarios will be supported by a cloud node, to which all other nodes will connect, sending the data for further analysis. All nodes run the universAAL IoT platform, allowing interoperability of the applications, as well as dealing with the distribution of the system. Devices are connected to gateways which in turn connect to cloud services. In our case we have three types of gateways, one per scenario; nevertheless one of the gateways is mobile and can come in the range of the other two. When this happens, the gateways will combine creating a single edge computing network, where special interactions can take place without the need of connecting to the cloud. This concept is called uSpace in universAAL [57]. For example, when the user is carrying his/her smartphone near an ACTIVAGE Centre, the ACTIVAGE Centre can use the uSpace and the user's smartphone as a hassle-free authentication mechanism, without the need of providing further credentials like user password, which elderly users may have trouble managing.

The distribution may also provide an extra feature; in this case the interspace communication (home-cloud, mobilecloud, and AC-cloud) can be configured to filter information. This filter is semantic; thus it is easy to create an understandable configuration tool for the user to create rules of data sharing and easily implementing data privacy [57].

As a result of the first iteration, in the assessment phase we have defined the evaluation framework and procedures. In particular, a set of Key Performance Indicators include quality of life, economic acceptability, and usability indicators in order to provide policy makers and other stakeholders with tools for the decision-making process. Assessment of user experience and benefit will take place during the testing, deployment, and operation and termination phase focusing on the following:

(i) Empowerment of users to live independently.

(ii) Improvement of quality of life of the users of the IoT solutions and their informal cares.

(iii) Supporting formal carers in their care of an assisted person. (iv) Improving efficiency and quality of social services.

(v) Reducing costs of providing social care services.

(vi) Postponing or preventing institutionalization.

(vii) Reducing opportunity costs (when, e.g., a caregiver can work instead of caring for a relative).

(viii) Increasing the number of IoT services.

Within the evaluation process of the ACTIVAGE deployment site of Madrid, we will measure the engagement of the users with the different services through the IoT collected data. We envision an analysis to study how the users interact with the applications, as there will be application usage metrics collection included in the IoT data collection system. Such analysis will also correlate this usage with the actual behaviour of the user, since we also will be able to access the activity data of the users (i.e., has the user gone on a walk when the system recommends it?).

Similarly to the Smart Cities solution for AHA usability, usefulness and ease of use will be assessed with a selection of users completing specific questionnaires.

\section{Discussion}

Smart Cities allow gathering big amounts of data from the environment (their application and services). In order to properly define and implement services for behavioural detection and intervention for empowering Active and Healthy Ageing, it has been needed to map the data that we can gather from the different sources available in a Smart City, with the relevant geriatric factors that allow us to identify behaviours related to MCI and frailty.

Smart living environments built using IoT devices allow retrieving a wide range of information coming from very different sources. Including contextual information always adds value to detected behaviours; however it is really needed when dealing with some concrete data, such as transportation and walking information, because there are some other factors, such as weather, that have an important influence in users behaviours (e.g., weather is an important factor when deciding to go for a walk). For this reason, examining all available open data services is very useful to gather contextual information.

In this context, it is important to highlight that ethical and privacy regulations need to be strengthened in order to ensure privacy and security of users' data [44].

Interview with users are an essential part of the design process. Even though some statements might look initially trivial, they at the very minimum confirm that the general idea has some value and, even for the most trivial statements, mark important requirements to the final system.

Most of the time, users will state impossible requirements with the current technology, but this marks the need for stretching the technology in that direction.

Another important aspect, with regard to user interviews and focus groups, is that they may be biased. The people that we interviewed are very active people and do a moderate use of the technology in their daily lives. Another biasing factor is that the people we eventually interviewed are representatives 
of the elderly users; in most cases this means that their recommendations are funded and based on actual knowledge of the users' problems. Both factors might contribute to these activities throwing an optimistic view, and sometimes faith, on what the technology can do for the users.

The use of the methodology of use cases as driver for the whole process is still valid. Even being an old tool, and sometimes even feeling constraining on what one can define the technology to do, it is still valuable process guidance. To the point that its use can find value on the system, it finds missing information, context, technology, and services, as well as being useful in other contexts such as nontechnological service definitions.

Failing to correctly define stakeholders' commitments or discovering that stakeholders cannot meet their commitment is a critical failure in the development process. In some methodologies this would be classified as a design problem; in our opinion, this type of failure has deeper negative impact on the delivery of the solution, not only in terms of delays and wasted resources, but also as these commitments are integral to offer the solution. Without them, mayor revision to many aspects of the solution needs to be refunded. This risk is the main reason we introduce the negotiation and agreement tasks in our methodology.

Our method has been useful for us to define the services that we need. If we apply more iterations we will still define even more services to implement. Yet the keystone to all services is interoperability; for the services that we propose in our results it is essential to share information, not only sources but the services themselves being a processing node of information which is then fed as input for other services. Interoperability of services is also a solution for unmet stakeholder commitment, as in these cases the service may be replaced by other providers as needed. The same concept is applicable at software and hardware levels; this is why we recommend pushing towards interoperability on all levels, as this offers more flexibility in the end solution.

Interoperability also allows enhancing the solution by adding services, applications, or devices on a later stage. Also interoperability works towards the reusability and internationalization of the solution, by enabling the provision of local services to be handled by other stakeholders.

As the system grows in number of services, the complexity of the interoperability problem will exponentially rise; thus a solution to manage such complexity is needed. We believe one such solution is semantical interoperability, which addresses the root problems of syntactical interoperability and enables the freedom of integrating in many different ways.

We recommend designing the evaluation framework to take into account not just technological aspects but every other aspect that has been defined in the requirement extraction. This way, the efficiency of the solution and the market feasibility can be contextualized and the chances for success are improved. It is also important to recycle evaluation tools and processes, adjusting them to the particular case, to reduce the burden of designing new methodologies. This would also mean that results could be scientifically valuable. We recommend the evaluation task to be a continuous task throughout the whole process, intervening to detect potential problems as soon as possible.

Prior to real life deployment, Living Lab testing is a very useful tool to evaluate the solution in close to real life conditions. In the case described in this manuscript, this Living Lab environment has been set up in the Smart House Living Lab of ETSIT UPM together with the Campus of International Excellence of Moncloa as Smart City Living Lab. Within this controlled environment, we could evaluate the solutions for indoor and outdoor detection, as well as interaction with public transportation buses present in the campus. During the first iteration for implementation of the solution based on the Smart Cities paradigm, evaluation at technical level (technical assessment) of services provided on mobility within Madrid was tested. These services include detection of different behaviours related to Basic and Instrumental Activities of Daily Living, such as going outside/inside home, usage of public transportation (buses), usage of transportation (other different than bus, e.g., car, bicycle), visiting friends, going to senior centres, going shopping, and visiting cultural points of interest. During the second iteration, which aims to evaluate the IoT paradigm on AHA solutions on Smart Cities, Living Lab testing allows validating the IoT architecture in terms of interoperability, integration, and interconnection of gateways and devices of different nature. Once assessed in the Living Lab context, the solution is ready to be scaled up and replicated in different scenarios.

In general, technologies for AHA have been more focused on providing support at home of the elderly. However, our results from the focus groups carried out so far show that services and applications deployed in Smart Cities enable Active and Healthy Ageing services in many more spaces, including the following:

(i) Outdoor spaces, such as parks, streets, or generally anywhere within the city.

(ii) Other indoor location different than homes, such as offices, places of worship, and shops.

(iii) Other living spaces like public services and infrastructures, such as transportation (i.e., stops, buses, underground, etc.).

IoT has demonstrated to add value to extend the accuracy of behavioural detection and increase number of services to be provided within a Smart City. IoT paradigm allows offering AHA services in an unobtrusive and transparent manner for the user, enhancing also their degree of adaptability and personalization.

Focus on citizens' engagement places them at the centre of the design and decisions taken within the city. Usually, Smart Cities have built their services mainly considering the point of view of transportation, energy efficiency, built environments, and so on, but not the care of their citizens, such as Active and Healthy Ageing. In this sense, the approach described in this paper includes the support to the well-being of elderly citizens as part of a Smart City strategical agenda.

We expect the evaluation of the end solution for Smart Cities and IoT to be a key entrance point and foster private and public investment, in order to start massive adoption of 
IoT solutions for AHA in Smart Cities, as well as to develop new business models and create new jobs.

\section{Conclusions}

We developed a methodology for implementing the cocreation framework on large scale projects. With this methodology, we were able to adapt solutions to fit particular paradigms, even combining paradigms, finding value for the different actors along the way. This value identification serves the purpose of optimizing the solution implementation.

Dividing the process into 3 phases helped pipeline the process, and we were able to run various projects in parallel without interfering with each other, even when we involved a subset of stakeholders in both and even when technologies used were similar. Phasing also allowed us to incorporate the outcomes of Smart Cities for AHA into the next iteration incorporating IoT components. The analysis phase has its importance by laying out the ground work for the rest of the development of the solution, especially assessing the viability. Requirement extraction from the users not only ensures that the usability and acceptability of the final system are optimal but also contributes as a preevaluation of the effectiveness of the use cases. Equally, UC definition must take into account the reusability of the use cases and many components of the system.

The adaptation phase has to be carefully balanced, and the solution is as much about the services as it is about the technology. The services are more difficult to be adapted, especially when these services include human resources, but when the change is supported with the technological component there is less resistance. As for the system development, the use cases together with service definition let us very easily identify the needed data. Once the data is identified, definition of exchange formats and information sources is easier. Driving the system design from the data perspective eases the proper management of security and privacy, as well as other data flows which in turn define the application flow. Data definitions will not only affect the application development, it is essential to analyze the required devices.

The analysis phase is critical to ensure the system is working properly before taking it into production. Evaluation of the system in different axis is very important; the results of this analysis will determine if the solution has actual value or not, and exactly how much value it is contributing to the stakeholders and users.

Results after the first iterative phase present a solution for AHA implemented in Smart Cities based on a series of use cases related to activities of daily living that allow identifying relevant geriatric factors which may be good indicators of frailty and/or cognitive decline. During the second iteration phase, IoT paradigm has been analysed and included as part of the solution. It has been demonstrated that IoT can add value to the solutions defined for Smart Cities in the AHA domain, and extend use cases with more data sources that also enable more functionalities.

This work must continue, as there is room for improving the methodology for the cocreation framework; for example, it can be adapted to other domains, so that it may be used for future projects. Thus it will be extremely interesting to research how to generalize the methodology to be domain and technology independent.

This research will be an iterative process in itself. By taking not only the methodology but also the services, and adapting them to research projects in different domains, with different base technological paradigms, and different target populations, we hope to slowly but surely mature the methodology.

With regard to the solutions reviewed in this paper, we will continue improving each of them, through successive iterations of the explained methodology. This will become even more apparent as the evaluations continue producing results.

\section{Conflicts of Interest}

The authors declare that there are no conflicts of interest regarding the publication of this paper.

\section{Acknowledgments}

This work is partially funded by the European Union under the Horizon 2020 Framework, through the projects City4Age (H2020, Contract no. 689731) and ACTIVAGE (H2020, Contract no. 732679).

\section{References}

[1] WHO., World Health Statistics 2014: A Wealth of Information on Global Public Health, 2014.

[2] M. Illario, M. Vollenbroek-Hutten, D. W. Molloy, E. Menditto, G. Iaccarino, and P. Eklund, "Active and healthy ageing and independent living," Journal of Aging Research, vol. 2015, Article ID 542183, 3 pages, 2015.

[3] J. Farrell and M. Nogues, "Operational Definition of Active and Healthy Aging (AHA): The European Innovation Partnership (EIP) on AHA Reference Site Questionnaire: Montpellier October 20-21, 2014, Lisbon July 2, 2015," Journal of the American Medical Directors Association, vol. 16, no. 12, pp. 1020-1026, 2015.

[4] Q. Yang and Z. Shen, "Active aging in the workplace and the role of intelligent technologies," in Proceedings of the 2015 IEEE/WIC/ACM International Joint Conference on Web Intelligence and Intelligent Agent Technology Workshops, WI-IAT Workshops 2015, pp. 391-394, December 2015.

[5] C. Parra, P. Silveira, I. K. Far et al., "Information technology for active ageing: A review of theory and practice," Foundations and Trends in Human-Computer Interaction, vol. 7, no. 4, pp. 351448, 2013.

[6] European Commission, European Innovation Partnership on Active and Healthy Ageing, 2017.

[7] B. Rechel, E. Grundy, J.-M. Robine et al., "Ageing in the European Union," The Lancet, vol. 381, no. 9874, pp. 1312-1322, 2013.

[8] A. Sixsmith and G. M. Gutman, Technologies for Active Aging, Springer, 2013.

[9] M. Satyanarayanan, "Pervasive computing: vision and challenges," IEEE Personal Communications, vol. 8, no. 4, pp. 10-17, 2001. 
[10] R. Costa, D. Carneiro, P. Novais et al., "Ambient assisted living," Advances in Soft Computing, vol. 51, pp. 86-94, 2009.

[11] M. Pieper, M. Antona, and U. Cortés, "Ambient Assisted Living," Ercim News, 2011.

[12] M. Bonaccorsi, L. Fiorini, F. Cavallo, A. Saffiotti, and P. Dario, "A Cloud Robotics Solution to Improve Social Assistive Robots for Active and Healthy Aging," International Journal of Social Robotics, vol. 8, no. 3, pp. 393-408, 2016.

[13] M. Drobics and S. Smith, Game-Based IT Solutions for Active and Healthy Aging, Springer, Cham, Germany, 2014.

[14] H. Chourabi, T. Nam, S. Walker et al., "Understanding smart cities: an integrative framework," in Proceedings of the 45th Hawaii International Conference on System Sciences (HICSS '12), pp. 2289-2297, January 2012.

[15] K. G. Fitzgerald and F. G. Caro, "An Overview of Age-Friendly Cities and Communities Around the World," Journal of Aging \& Social Policy, vol. 26, no. 1-2, pp. 1-18, 2014.

[16] European Commission, European Innovation Partnership Smart Cities and Communities, 2017.

[17] A. Ramaswami, A. G. Russell, P. J. Culligan, K. Rahul Sharma, and E. Kumar, "Meta-principles for developing smart, sustainable, and healthy cities," Science, vol. 352, no. 6288, pp. 940-943, 2016.

[18] T. Buffel, P. McGarry, C. Phillipson et al., Developing AgeFriendly Cities: Case Studies from Brussels and Manchester and Implications for Policy and Practice, Springer, Cham, Germany, 2016.

[19] R. Das, "A Survey on the internet of things solutions for the elderly and disabled: applications, prospects, and challenges," International Journal of Computer Networks and Applications, vol. 4, no. 3, pp. 1-9, 2017.

[20] G. Fico, J. Montalva, A. Medrano et al., "Co-creating with consumers and stakeholders to understand the benefit of internet of things in smart living environments for ageing well: The approach adopted in the madrid deployment site of the activage large scale pilot," in Proceedings of the Joint Conference of the European Medical and Biological Engineering Conference, EMBEC 2017 and Nordic-Baltic Conference on Biomedical Engineering and Medical Physics, NBC 2107, pp. 1089-1092, June 2017.

[21] E. I. Konstantinidis, G. Bamparopoulos, A. Billis, and P. D. Bamidis, "Internet of Things for an Age-Friendly Healthcare," Studies in Health Technology and Informatics, vol. 210, pp. 587591, 2015.

[22] AIOTI, Alliance for Internet of Things Innovation, 2017.

[23] I. Arbel, K. Baker, T. Bailey, M. Bouraoui, and I. Chartier, AIOTI WG5-Smart Living Environment for Ageing Well, 2015.

[24] D. Wortley, J.-Y. An, and A. Heshmati, “Tackling the challenge of the aging society: Detecting and preventing cognitive and physical decline through games and consumer technologies," Health Informatics Journal, vol. 23, no. 2, pp. 87-93, 2017.

[25] M. Zallio, D. Berry, and N. Casiddu, "Adaptive environments for enabling senior citizens: An holistic assessment tool for housing design and IoT-based technologies," in Proceedings of the 3rd IEEE World Forum on Internet of Things, WF-IoT 2016, pp. 419424, December 2016.

[26] A. Melis, M. Prandini, L. Sartori, and F. Callegati, "Public Transportation, IoT, Trust And Urban Habits," in Internet Science, F. Bagnoli, A. Satsiou, and I. Stavrakakis, Eds., vol. 9934 of Lecture Notes in Computer Science, pp. 318-325, Springer, Berlin, Germany, 2016.
[27] Y. Shibata and G. Sato, "IoT Based Mobility Information Infrastructure in Challenged Network Environment toward Aging Society," in Proceedings of the 31st IEEE International Conference on Advanced Information Networking and Applications Workshops, WAINA 2017, pp. 645-648, March 2017.

[28] C. Kulczycki, R. Genoe, H. Marston, S. Freeman, and C. Musselwhite, If I Want to Know Anything I Just Google It": Older Adults' Functional and Social Leisure Activities And Technology, 2016.

[29] P. J. McCullagh and J. C. Augusto, “The Internet of Things: The Potential to Facilitate Health and Wellness," CEPIS Upgrad, vol. XII, no. 1, pp. 59-68, 2011.

[30] M. N. Kamel Boulos, A. D. Tsouros, and A. Holopainen, "'Social, innovative and smart cities are happy and resilient': insights from the WHO EURO 2014 International healthy cities conference," International Journal of Health Geographics, vol. 14, article 3, 2015.

[31] M. N. K. Boulos and N. M. Al-Shorbaji, "On the internet of things, smart cities and the WHO healthy cities," International Journal of Health Geographics, vol. 13, no. 1, article 10, 2014.

[32] M. Carmena, "La alcaldesa Manuela Carmena presenta Madrid, ciudad amigable con las personas mayores," QMAYOR MAGAZINE, 2017.

[33] http://www.city4ageproject.eu.

[34] P. Paolini, N. Di Blas, S. Copelli, and F. Mercalli, "City4Age: Smart cities for health prevention," in Proceedings of the 2nd IEEE International Smart Cities Conference, ISC2 2016, pp. 1-4, September 2016.

[35] H. Camacho, L. Cámara, R. Cascante, and H. Sainz, 'The Logical Framework Approach: 10 Case Studies, 2001.

[36] H. Camacho, L. Camara, R. Cascante et al., Fundación de Cooperación, El Enfoque del marco lógico, 10 casos prácticos: cuaderno para la identificación y diseño de proyectos de desarrollo, Fundación CIDEAL, 2001.

[37] K. Örtengren, The Logical Framework Approach: A Summary of The Theory behind the LFA Method, 2004.

[38] W. J. Jackson, "Designing Projects and Project Evaluations Using The Logical Framework Approach," 1997, https://www .researchgate.net/profile/William_Jackson12/publication/265012218_Designing_Projects_and_Project_Evaluations_Using_The _ Logical_Framework_Approach/links/565e604708ae4988a7bd5818.pdf.

[39] D. Salvi, J. B. Montalvá Colomer, M. T. Arredondo, B. PrazakAram, and C. Mayer, "A framework for evaluating Ambient Assisted Living technologies and the experience of the universAAL project," Journal of Ambient Intelligence and Smart Environments, vol. 7, no. 3, pp. 329-352, 2015.

[40] J. B. Montalvá Colomer, D. Salvi, M. F. Cabrera-Umpierrez et al., "Experience in evaluating AAL solutions in living labs," Sensors, vol. 14, no. 4, pp. 7277-7311, 2014.

[41] W. W. Royce, "Managing the development of large software systems," IEEE WESCON, vol. 26, pp. 1-9, 1970.

[42] J. Rumbaugh, I. Jacobson, and G. Booch, The Unified Modeling Language Reference Manual, Addison-Wesley, 2005.

[43] K. Bittner and I. Spence, Use Case Modeling, Addison Wesley, 2003.

[44] http://eur-lex.europa.eu/legal-content/EN/TXT/?uri= CELEX\%3A32016R0679.

[45] L. P. Fried, C. M. Tangen, J. Walston et al., "Frailty in older adults: evidence for a phenotype," The Journals of Gerontology. Series A, Biological Sciences and Medical Sciences, vol. 56, no. 3, pp. M146-M156, 2001. 
[46] https://consultgeri.org/try-this/general-assessment/issue-23.

[47] https://www.lst.tfo.upm.es/smart-house.

[48] http://www.campusmoncloa.es/.

[49] https://decide.madrid.es/.

[50] https://sites.google.com/a/tcd.ie/share-frailty-instrumentcalculators/.

[51] https://www.alz.org/documents_custom/minicog.pdf.

[52] J. Martínez de la Iglesiaa, R. DueñasHerrerob, M. Carmen Onís Vilchesa, C. Aguado Tabernéa, C. Albert Colomerc, and R. Luque Luquec, "Adaptación y validación al castellano del cuestionario de Pfeiffer (SPMSQ) para detectar la existencia de deterioro cognitivo en personas mayores e 65 años," Medicina Clínica, vol. 117, no. 4, pp. 129-134, 2001.

[53] J. Nielsen, Ten Usability Heuristics, 2005.

[54] J. Brooke, "evaluation in industry and undefined 1996," in SUS-A Quick And Dirty Usability Scale, 1996, https://books.google.com/?hl=ar.

[55] V. Venkatesh, M. G. Morris, G. B. Davis, and F. D. Davis, "User acceptance of information technology: toward a unified view," MIS Quarterly: Management Information Systems, vol. 27, no. 3, pp. 425-478, 2003.

[56] http://www.madrid.es/portales/munimadrid/es/Inicio/ El-Ayuntamiento?vgnextfmt $=$ default\&vgnextchannel= channel=069e242ab26010 VgnVCM100000dc0ca8c0RCRD.

[57] A. Mantelero, “The EU Proposal for a General Data Protection Regulation and the roots of the right to be forgotten," Computer Law and Security Review, vol. 29, no. 3, pp. 229-235, 2013. 


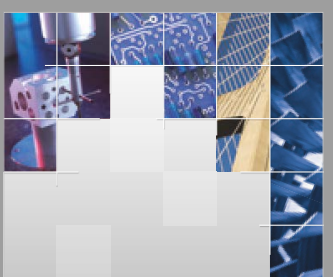

\section{Enfincering}
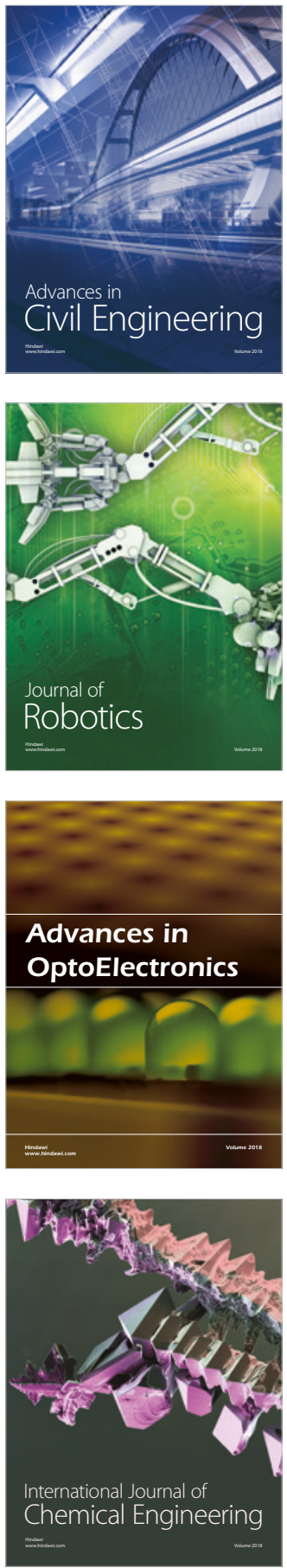

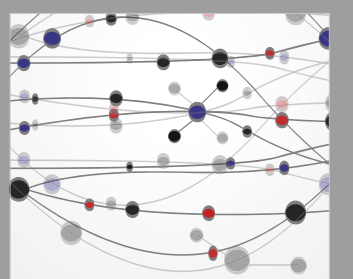

\section{Rotating \\ Machinery}

The Scientific World Journal

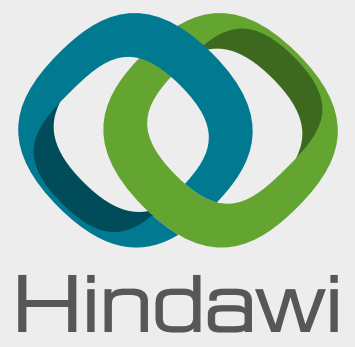

Submit your manuscripts at

www.hindawi.com
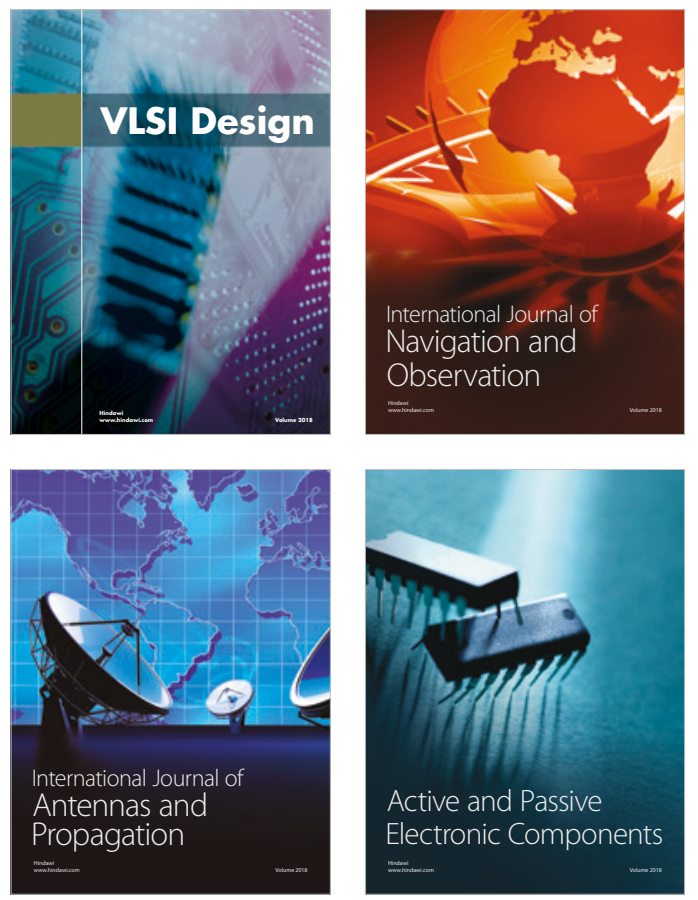
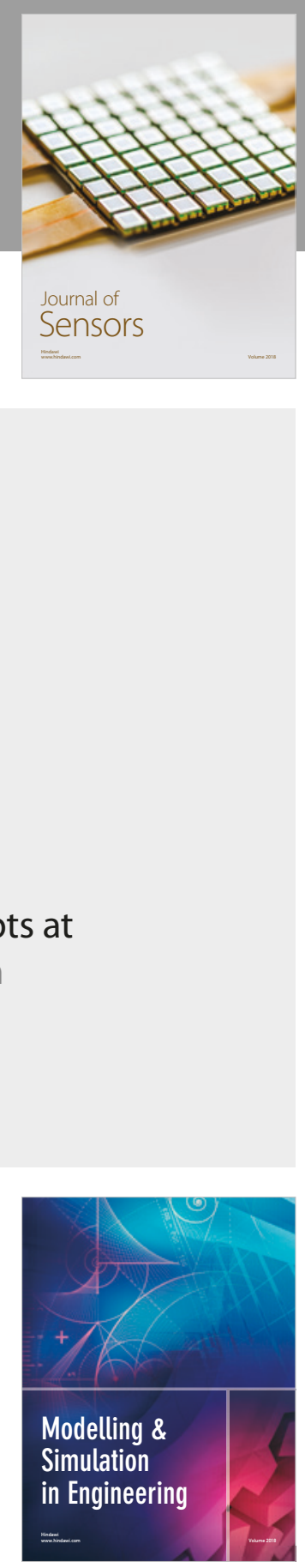

\section{Advances \\ Multimedia}
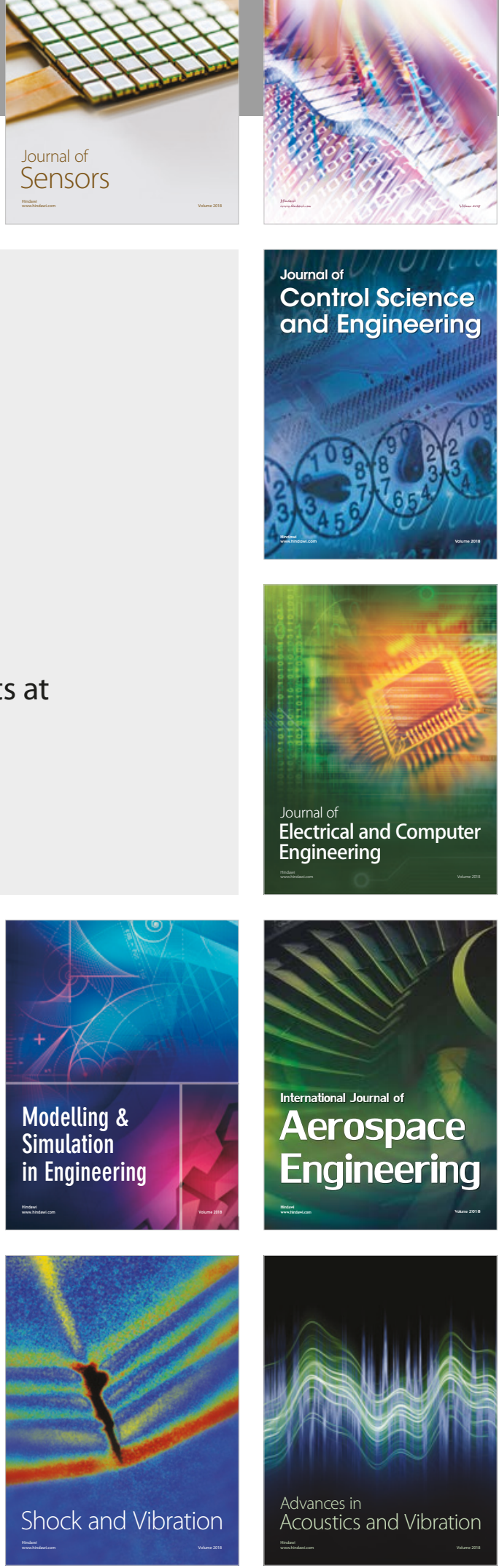